\title{
Activation of PKR by RNA misfolding: HDV ribozyme dimers activate PKR
}

\author{
LAURIE A. HEINICKE ${ }^{1}$ and PHILIP C. BEVILACQUA ${ }^{2}$ \\ Department of Chemistry, Center for RNA Molecular Biology, The Pennsylvania State University, University Park, Pennsylvania 16802, USA
}

\begin{abstract}
Protein Kinase R (PKR), the double-stranded RNA (dsRNA)-activated protein kinase, plays important roles in innate immunity. Previous studies have shown that PKR is activated by long stretches of dsRNA, RNA pseudoknots, and certain single-stranded RNAs; however, regulation of PKR by RNAs with globular tertiary structure has not been reported. In this study, the HDV ribozyme is used as a model of a mostly globular RNA. In addition to a catalytic core, the ribozyme contains a peripheral 13-bp pairing region (P4), which, upon shortening, affects neither the catalytic activity of the ribozyme nor its ability to crystallize. We report that the HDV ribozyme sequence alone can activate PKR. To elucidate the RNA structural basis for this, we prepared a number of HDV variants, including those with shortened or lengthened P4 pairing regions, with the anticipation that lengthening the P4 extension would yield a more potent activator since it would offer more base pairs of dsRNA. Surprisingly, the variant with a shortened P4 was the most potent activator. Through native gel mobility and enzymatic structure mapping experiments we implicate misfolded HDV ribozyme dimers as the PKR-activating species, and show that the shortened P4 leads to enhanced occupancy of the RNA dimer. These observations have implications for how RNA misfolding relates to innate immune response and human disease.
\end{abstract}

Keywords: PKR; HDV; RNA dimer; RNA misfolding; innate immunity

\section{INTRODUCTION}

Hepatitis delta virus (HDV) is a satellite virus of hepatitis B virus (HBV), where coinfection by $\mathrm{HDV}$ leads to a more virulent form of the infection (Lai 1995; Lazinski and Taylor 1995; Karayiannis 1998). The 1.7-kb circular, singlestranded RNA genome of HDV is responsible for making genomic and antigenomic strands of RNA. Replication of the HDV genome is assisted by self-cleavage of a semiglobular (Ferre-D’Amare et al. 1998), 84-nt ribozyme located in both genomic and antigenomic RNA strands, which serves to linearize concatamers. Sequence downstream from the ribozyme, referred to as the "attenuator" sequence, sequesters native ribozyme pairings and forms a long rod-like structure (Fig. 1; Wang et al. 1986; Lazinski and Taylor 1993, 1995).

Two previous studies characterized PKR activation by a 482-nt segment of the HDV genomic RNA (annotated as

\footnotetext{
${ }^{1}$ Present address: Department of Medicine, University of Pennsylvania School of Medicine, Philadelphia, PA 19104, USA

${ }^{2}$ Corresponding author

E-mail pcb5@psu.edu

Article published online ahead of print. Article and publication date are at http://www.rnajournal.org/cgi/doi/10.1261/rna.034744.112.
}

$-207 / 275$, where 1 is the first nucleotide of the ribozyme) (Robertson et al. 1996; Circle et al. 1997). This region of RNA includes the $\sim 84$-nt ribozyme and forms its rod-like structure due to native ribozyme base pairs being sequestered by attenuator sequence (Fig. 1A, top structure). Within this rod-like structure, there are no stretches of dsRNA greater than 20-bp. In addition to reporting activation of PKR by this long segment of HDV, the investigators mapped the PKR-binding site to the ribozyme-containing portion of the rod-like structure. This particular site has also been reported to form a cruciform structure (Fig. 1A, bottom structure; Branch and Robertson 1991; Diegelman-Parente and Bevilacqua 2002).

Prior studies have shown that PKR is activated by long dsRNAs, typically $>33$ bp in length (Manche et al. 1992; Zheng and Bevilacqua 2004). In addition, PKR is known to be activated by highly structured RNA domains of hepatitis C virus (HCV) (Shimoike et al. 2009; Toroney et al. 2010) and a pseudoknotted human IFN- $\boldsymbol{\gamma}$-mRNA (Ben-Asouli et al. 2002; Cohen-Chalamish et al. 2009). Unlike the above activators, the HDV ribozyme is semiglobular, although it contains a protruding 13-bp pairing region (P4). Globular RNA activators of PKR with the characteristics of HDV have not been previously examined. 
A

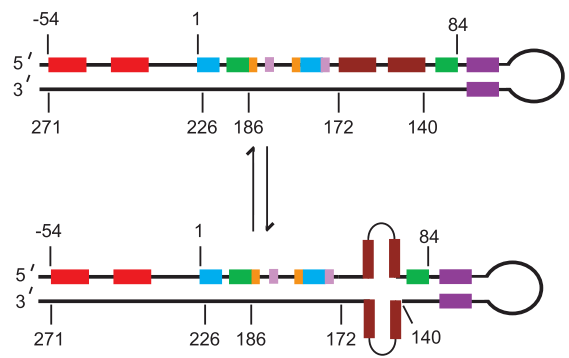

B

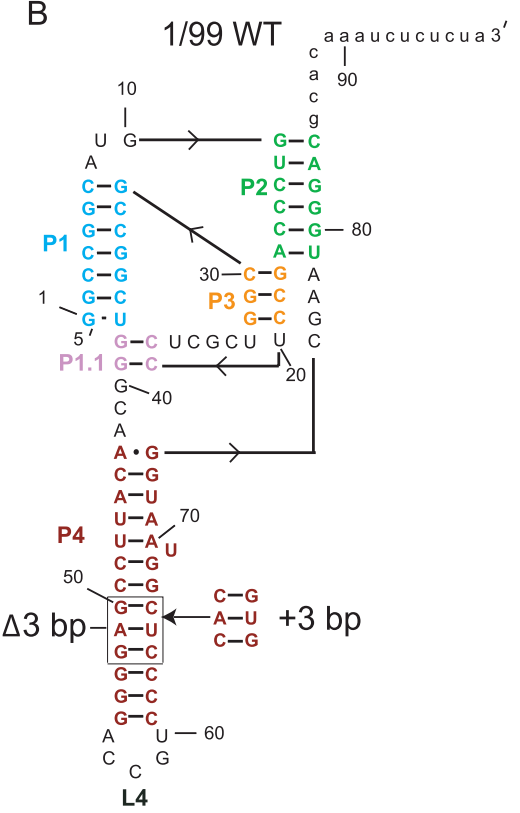

FIGURE 1. Secondary structures of HDV genome segment and HDV ribozyme. (A) Portion of the HDV genome illustrating rod-like (top) and alternative cruciform (bottom) structures (Branch and Robertson 1991; Diegelman-Parente and Bevilacqua 2002). Color-coding represents two strands that either base pair in the ribozyme (colors match those in $B$ ) or in the upstream $\mathrm{P}(-1)$ region between -54 and -1 (Chadalavada et al. 2000). (B) Secondary structure for 1/99 WT and alterations in the 1/99 P4 variants, $\Delta 3 \mathrm{bp}$ and $+3 \mathrm{bp}$. Variant $1 / 99$ $\Delta 3$ bp was prepared by removing the following six nucleotides: G50, A51, G52, C64, U65, and C66 (all six nucleotides boxed), while $1 / 99+3$ bp was prepared by adding the six nucleotides at the position shown.

In this report, we focus on the regulation of PKR by the 1/99 HDV ribozyme sequence-a much smaller fragment of the previously reported PKR-regulating construct, and one that is missing the attenuator-and investigate the role of the P4 region in activation. Variants of 1/99 were prepared with shortened or lengthened $\mathrm{P} 4$ regions, with expectation that lengthening P4 would lead to increased PKR activation since it would offer more base pairs of dsRNA. Surprisingly, "shortening" P4 increased PKR activation. Herein, we report that ribozyme dimers, with an extended kissing loop, are the activating species and that shortening P4 enhances the extent of dimer formation and PKR activation. We discuss possible biological implications of this activity.

\section{RESULTS AND DISCUSSION}

\section{Activation of PKR by monomer/dimer mixtures of 1/99 HDV variants}

Our lab has been interested in identifying and characterizing RNA motifs that regulate PKR activity (Zheng and Bevilacqua 2004; Nallagatla et al. 2007; Heinicke et al. 2009, 2011; Toroney et al. 2010); we thus chose to examine activation of PKR by the semiglobular HDV ribozyme. Various lengths of the HDV genome, including wild-type uncleaved and cleaved, and the catalytically unreactive $\mathrm{C} 75 \mathrm{U}$ forms of $-54 / 271,-54 / 186,-54 / 172,-54 / 140$, and $-54 / 99$ were initially tested for PKR activation. All RNAs activated PKR to some extent, with optimal RNA concentrations of $0.5 \mu \mathrm{M}$ for longer RNAs and $5 \mu \mathrm{M}$ for shorter RNAs. There was no clear trend in the ability of WT versus C75U to activate PKR (Heinicke 2010), suggesting that the activating species is not the monomeric RNA with catalytic tertiary structure. We chose to focus this study on the $1 / 99$ WT construct, which was the minimal RNA motif able to activate PKR.

Biochemical and structural analyses indicate that this region is mostly globular, but with a long protruding pairing termed P4 (Fig. 1; Ferre-D'Amare et al. 1998; Chadalavada et al. 2000). Early catalytic studies on the HDV ribozyme showed that shortening P4 does not significantly affect catalytic activity (Been and Wickham 1997) and that P4-shortened forms readily crystallize in catalytically relevant conformations (Ferre-D'Amare et al. 1998). The P4 loop sequence (L4) is largely self-complementary (ACCGU); thus, we hypothesized that two molecules of HDV may interact through L4 as kissing hairpins. This interaction would make a $\sim 28$-bp dsRNA segment onto which two PKR molecules could bind and autophosphorylate. Such RNA lengths are near the minimal activating length of $\sim 33$ bp (Manche et al. 1992; Zheng and Bevilacqua 2004). Thus, if this model were correct, shortening P4 would decrease PKR activation, while lengthening it would increase activation. Subsequent experiments would prove that this model is too simple.

We designed a shortened $\mathrm{P} 4$ variant with $3 \mathrm{bp}$ removed, referred to as "1/99 $\Delta 3 \mathrm{bp}$," and a lengthened P4 variant that has 3 bp inserted, referred to as " $1 / 99+3$ bp" (Fig. 1B). (Note that we avoided weakening P4 through the introduction of bulges, as this would result in bulges in the concomitant dimers, which would very likely prevent PKR activation as recently shown [Heinicke et al. 2011].) For this study, all three 1/99 variants were prepared from self-cleaved transcripts that begin at -54 and end with 99 and were isolated on a denaturing 6\% PAGE. The extent of cleavage during transcription was extensive, with $-54 / 99 \Delta 3$ bp cleaving up to $\sim 80 \%$, and $-54 / 99$ WT and $-54 / 99+3$ bp cleaving to $\sim 90 \%$. These extents of cleavage provided adequate cleaved ribozyme for the present study. 
The three HDV variants were examined for sample heterogeneity by native gel-mobility analysis (Fig. 2A). Monomeric HDV ribozyme is known to be well-folded in $200 \mathrm{mM} \mathrm{NaCl}$ and $10 \mathrm{mM} \mathrm{MgCl}_{2}$ (Brown et al. 2004); however, effects of salt on HDV multimerization have not been investigated. We examined sample heterogeneity of the total sample in three salt conditions: First, RNA was denatured at $90^{\circ} \mathrm{C}$ for $1 \mathrm{~min}$, then incubated at $55^{\circ} \mathrm{C}$ for 10 min, followed by incubation at room temperature for 10 min, and then treated with an equal volume of (1) TE, (2) $\mathrm{TEK}_{400} \mathrm{M}_{20}$, or (3) $\mathrm{TEN}_{400} \mathrm{M}_{20}$ (see Materials and Methods for buffer shorthand), such that the final salt for (2) and (3) was $200 \mathrm{mM} \mathrm{KCl}$ (or $\mathrm{NaCl}$ ) and $10 \mathrm{mM} \mathrm{MgCl}_{2}$. As shown in Figure 2A, changing the salt did not affect electrophoretic mobility, but increasing the RNA concentration yielded more dimer for all variants, consistent with Le Châtelier's principle (Fig. 2A, cf. lanes 6-8 with 3-5, lanes 12-14 with 9-11, or lanes 18-20 with 15-17). (See Materials and Methods for confirmation of monomer and dimer species according to tRNA markers.) Notably, $1 / 99 \Delta 3$ bp formed the most dimer $(\sim 50 \%)$, while $1 / 99$ WT and $1 / 99+3$ bp formed only small amounts of dimer $(\sim 10 \%)$. Increased dimer formation in $1 / 99 \Delta 3$ bp is likely due to destabilization of P4 in the monomeric form. We note that enhanced dimerization of the shortened form of the ribozyme does not contradict the results of Been and Wickham (1997), that shortening P4 does not affect catalytic activity in that their experiments were conducted with trace amounts of radiolabeled RNA, which are unlikely to dimerize, while our experiments were conducted with $20 \mu \mathrm{M}$ of RNA (Fig. 2A).

To test for a correlation between HDV sample multimerization and PKR activity, we performed activation assays using RNA that had been renatured in the ways that provide the various species of Figure 2A using final conditions of $\mathrm{TEN}_{100} \mathrm{M}_{5}$. As shown in Figure $2 \mathrm{~B}$, the 1/99 $\Delta 3$-bp variant, which was left as a monomer/dimer mixture in this instance, activated PKR significantly more potently than $1 / 99$ WT or $1 / 99+3$ bp (13- to 34 -fold more in the presence of $1 \mu \mathrm{M}$ RNA). These trends in activation correlate with the greater amount of dimer in the native gel (Fig. 2A), implicating dimer in PKR activation. Also, consistent with previous reports, PKR activation exhibits

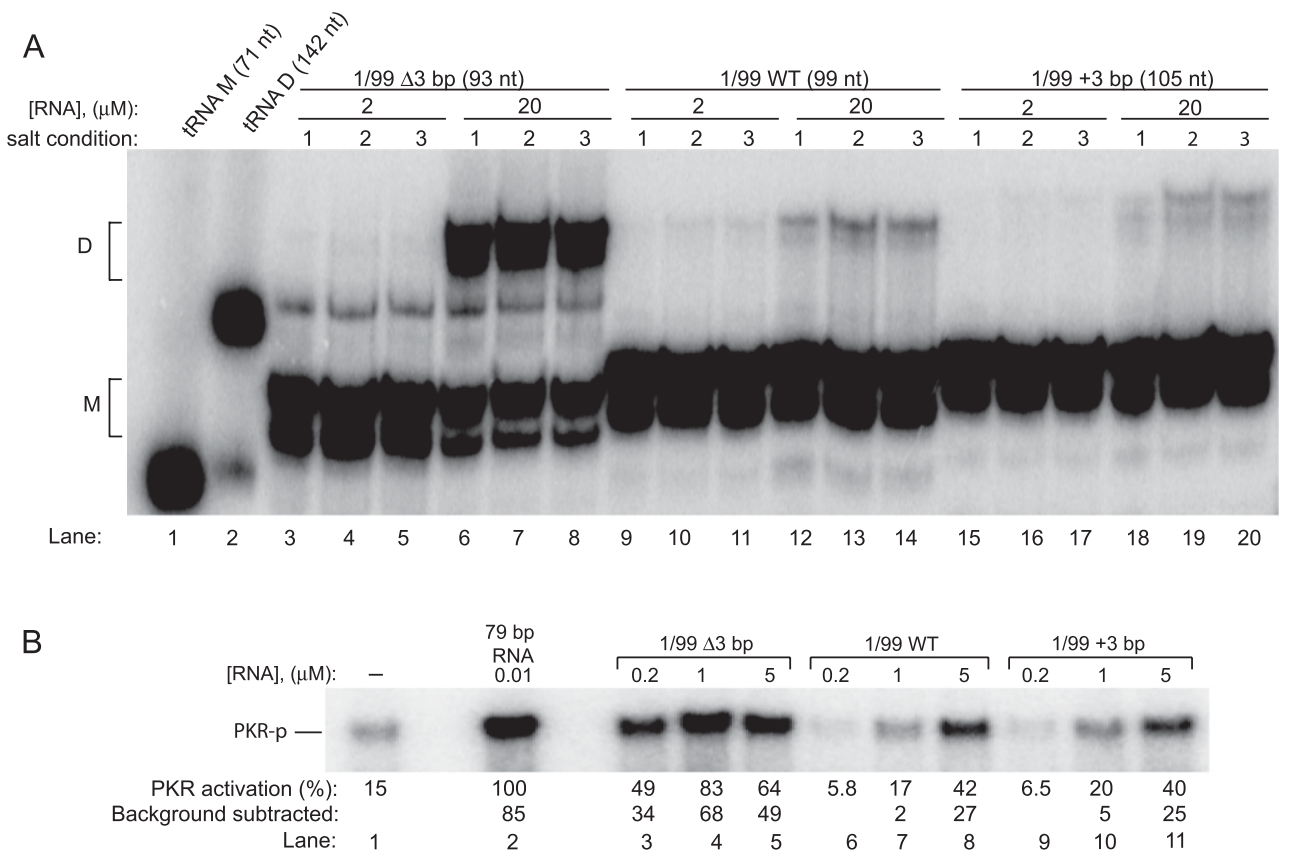

FIGURE 2. Native gel analysis of HDV dimerization and its association with PKR activation. (A) Native gel analysis of RNA. Gel is $10 \%$ native PAGE run in $\mathrm{THEM}_{4}$. 1/99 $\Delta 3 \mathrm{bp}$, WT, and +3 bp were renatured at 2 or $20 \mu \mathrm{M}$ concentrations with trace $5^{\prime}$-end labeled RNA in TE, by incubating at $90^{\circ} \mathrm{C}$ for $1 \mathrm{~min}$, followed by room temperature for $10 \mathrm{~min}$, then $55^{\circ} \mathrm{C}$ for $10 \mathrm{~min}$, followed by incubation at room temperature for $10 \mathrm{~min}$. The sample was then mixed with an equal volume of one of the following salt conditions (labeled in gel): (1) TE, (2) TEK $\mathrm{T}_{400} \mathrm{M}_{20}$, or (3) $\mathrm{TEN}_{400} \mathrm{M}_{20}$; final ionic concentrations in 2 and 3 were $200 \mathrm{mM} \mathrm{KCl}$ (or NaCl) and $10 \mathrm{mM} \mathrm{MgCl}$. Number of nucleotides in cleaved monomer HDV is provided above the gel. The faster migrating bands are assigned as monomer (M) and the slower migrating bands as dimer (D) as described in the Materials and Methods; assignment of these bands is facilitated by structure mapping (see below) and by comparison to lanes 1 and 2, which are tRNA monomer (M) and dimer (D), with the dimer prepared as per Wittenhagen and Kelley (2002) and Roy et al. (2005). (The minor, faster-mobility band associated with $\mathrm{M}$ and $\mathrm{D}$ was not always present in native gels [e.g., absent in Figs. 3A, 4B] and may represent alternative RNA structures induced by the presence of divalent salt in THEM $_{4}$ buffer, which is absent in Figs. 3A, 4B.) (B) PKR activation by HDV variants containing a mixture of the $\mathrm{M}$ and $\mathrm{D}$ species. Renaturation and ionic conditions are provided in the Materials and Methods. A no-RNA lane is provided, and phosphorylation activities are normalized to $0.01 \mu \mathrm{M} 79 \mathrm{bp}$ RNA. Both no-RNA and 79-bp RNA lanes contain a final concentration of $100 \mathrm{mM}$ $\mathrm{NaCl}$ and $5 \mathrm{mM} \mathrm{MgCl}_{2}$. The no-RNA lane was subtracted from each lane in order to provide RNA-dependent activation values. 
a bell-shaped dependence on RNA concentration for the most potent RNA activator (see Fig. $2 \mathrm{~B}, 1 / 99 \Delta 3 \mathrm{bp}$ ). The bell shape arises because high concentrations of dsRNA activators titrate PKR into monomers, thus preventing PKR dimerization and activation (Lemaire et al. 2008).

\section{Activation of PKR by purified HDV dimer}

Next, we tested whether activation was indeed coming from the dimeric form of the RNA. We performed activation and structural analyses using gel-purified HDV RNA dimer, following a procedure that we recently developed (Heinicke et al. 2009). Briefly, the RNA was renatured, monomer and dimer bands were separated on a native gel, and bands were gently eluted into buffer, precipitated, dissolved in buffer, and stored at $-20^{\circ} \mathrm{C}$ (see Materials and Methods for details).

An analytical native gel was run on the isolated monomeric and dimeric RNA species to assure that they retained their monomer and dimer identities (Fig. 3A); these species were then tested for their ability to activate PKR (Fig. 3B). To remove possible dimer contaminants from monomer, which is problematic because of their activating potential, native gel-purified 1/99 WT monomer was in some cases heated to $90^{\circ} \mathrm{C}$ (see Materials and Methods) and then added to an equal volume of $\mathrm{TEN}_{200} \mathrm{M}_{20}$. On the other hand, HDV dimer was treated "without" heating, and then added to an equal volume $\mathrm{TEN}_{200} \mathrm{M}_{20}$, in order to

A

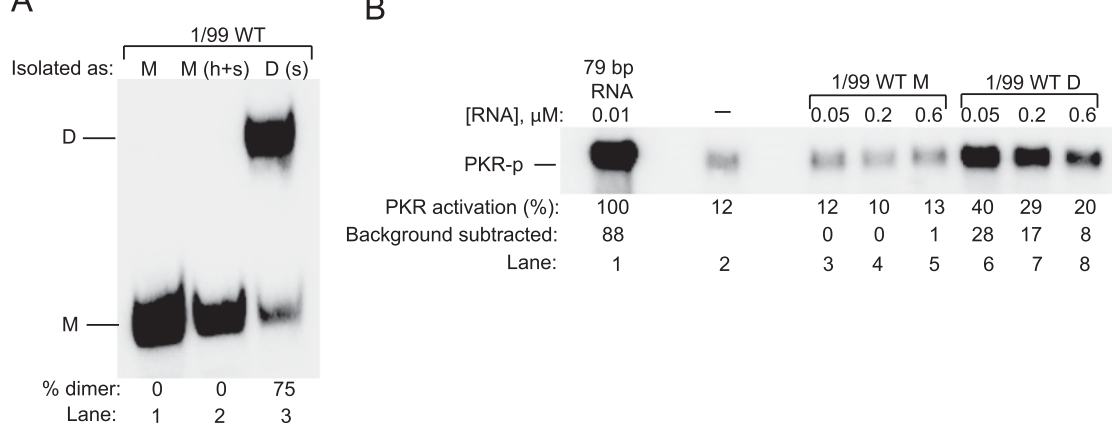

FIGURE 3. Dimers of the HDV ribozyme activate PKR. (A) Analytical native gel analysis of isolated and purified 1/99 WT monomer and dimer. Gel is 10\% native PAGE run in $0.5 \times$ TBE. RNA monomers and dimers were first isolated as described in the Materials and Methods section "Purification of RNA monomers and dimers from native gels;" purification gel not shown. Then, certain monomer and dimer samples were added to an equal volume $\mathrm{TEN}_{200} \mathrm{M}_{20}$ (indicated with " $\mathrm{s}$ " for salt above the gel), followed by incubation at room temperature for 10 min. Prior to adding $\mathrm{TEN}_{200} \mathrm{M}_{20}$, certain monomer samples were heat renatured (indicated with " $\mathrm{h}$ " for heat above the gel) to remove possible dimer contaminants by incubating at $90^{\circ} \mathrm{C}$ for $1 \mathrm{~min}$, followed by room temperature for $10 \mathrm{~min}$, then $55^{\circ} \mathrm{C}$ for $10 \mathrm{~min}$, followed by incubation at room temperature for $10 \mathrm{~min}$. Both monomer-untreated $(\mathrm{M})$ and monomertreated with heat and salt $(\mathrm{M}(\mathrm{h}+\mathrm{s}))$ are shown. Percent dimer is provided. This gel confirms that dimer identity has been largely retained and that, most importantly, monomer identity has been retained after native gel purification. (B) PKR activation by isolated and purified 1/99 WT HDV monomer and dimer. A no-RNA lane is provided, and phosphorylation activities are normalized to $0.01 \mu \mathrm{M}$ 79-bp RNA. Both no-RNA and 79-bp RNA lanes contain $50 \mathrm{mM} \mathrm{NaCl}$ and $5 \mathrm{mM} \mathrm{MgCl}_{2}$. The no-RNA lane was subtracted from each lane in order to provide RNAdependent activation values. discourage monomer formation and keep the dimer kinetconcentration decreasing monovalent salt at early time points has been shown to enhance activation signal (Heinicke et al. 2011). The 1/99 WT isolated as dimer remained $\sim 75 \%$ dimer after native gel purification (Fig. 3A, lane 3), while the RNA lated as monomer showed no detectable dimer (Fig. 3A, 1,2). Dimer retention is likely due to kinetic trapping, above background (cf. lanes 3-5 and lane 2), while the dimer because monomer does not activate PKR; on the other hand, our successful removal of dimer from monomer preparations (Fig. 3A, lanes 1,2) was key because dimer activates PKR.

Absence of PKR activation by 1/99 WT monomer orts the inability of a globular RNA structure, conlow as $0.05 \mu \mathrm{M}$ (Fig. 3B). Indeed, the optimal activation RNA has shifted at least 100-fold lower than in a heterogeneous mixture (cf. Figs. $2 \mathrm{~B}$ and $3 \mathrm{~B}$ ). Even lower concentrations of HDV dimer were tested for PKR activation and resulted in less activation (Supplemental Fig. S1), once again revealing a bell-shaped dependence on RNA concentration and suggesting that $0.05 \mu \mathrm{M}$ dimer is the optimal concentration for PKR activation. We previously noted that perfect 79-bp RNA optimally activates PKR between 0.01 and $0.1 \mu \mathrm{M}$ (Zheng and Bevilacqua 2004). Thus, it appears that WT dimer interacts with PKR nearly as tightly as perfect 79-bp dsRNA. Overall, these findings support HDV ribozyme dimers, and not monomers, as being the activators of PKR. We also found that $1 / 99 \Delta 3 \mathrm{bp}$ and $1 / 99+3 \mathrm{bp}$ activated PKR as dimers but not monomers (Supplemental Fig. S2).

\section{Secondary structure mapping of HDV monomers and dimers}

The above experiments established a strong correlation between $\mathrm{HDV}$ 
ribozyme dimerization and PKR activation. To further our understanding of the molecular basis of PKR activation by HDV dimers, secondary structure mapping of monomer and dimer was performed (Fig. 4). Purified monomer and dimer RNA samples used for structure mapping retained their expected oligomeric identities on a native gel (Fig. 4B).

Enzymatic structure mapping of 1/99 WT monomer yielded a cleavage pattern in agreement with the published monomeric HDV ribozyme secondary structure (Been and Wickham 1997; Ferre-D'Amare et al. 1998), with L4 giving very intense single-stranded cleavages (Fig. 4A,C). The secondary structure data for 1/99 WT dimer, on the other hand, revealed the near absence of single-stranded cleavages in L4, consistent with the P4-kissing extended dimer depicted in Figure 4D. Residues A8 through C13 map differently for monomer and dimer, with more cleavage by the dsRNA-specific RNase V1 in monomer. This suggests that the dimer structure is not simply the native globular structure with a kissing P4 (Fig. 4D). The double-stranded cleavages observed in the monomer samples are reduced near G10 (RNase V1 cleavages migrate slower by $\sim 1 \mathrm{nt}$ in this region due to leaving a $3^{\prime} \mathrm{OH}$ ) (Brown and Bevilacqua 2005), consistent with $\mathrm{J} 1 / 2$ bend here. An absence of these RNase V1 cleavages in the dimer could result from A8 bulge and C13 mismatches depicted in the model in Figure 4D. This and other regions of cleavage superimposed on the secondary structure model in Figure 4D suggest that the PKR-activating HDV dimer is structurally distinct from the native globular HDV monomer, and is instead an extended dimer. It should also be noted that RNase V1 tends to cleave helical regions of at least 4-6 nt in length (Lowman and Draper 1986), which may account for the absence of V1 cleavage in the 44-47 bp of P4, which are also adjacent to tertiary structure, a bulged $\mathrm{U}$, and have weak AU-rich pairing. Additionally, the more robust RNase T1-which is active in cleaving this RNA elsewhere-fails to cleave after

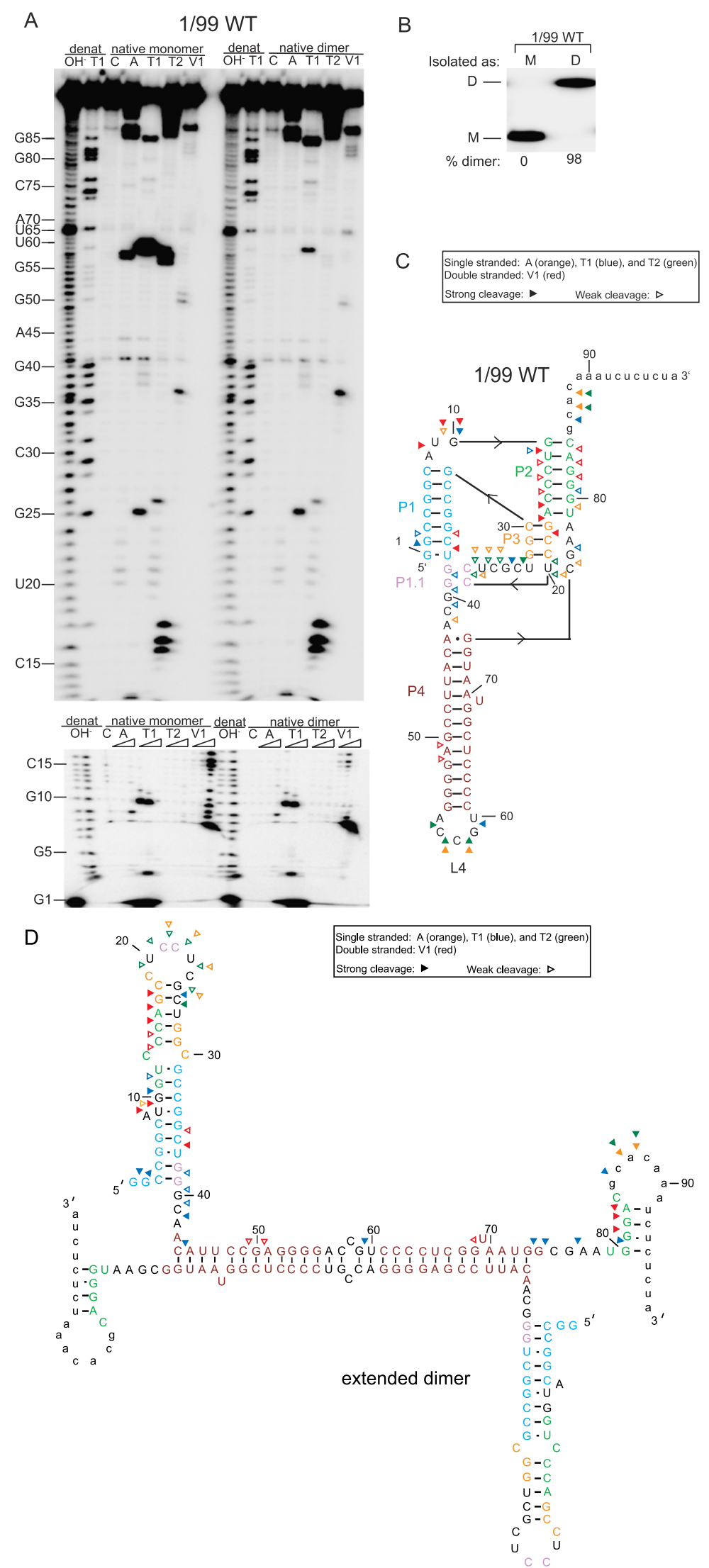

FIGURE 4. (Legend on next page) 
any of the G's in the $\mathrm{P} 4$ region; thus, the $\mathrm{P} 4$ region in both the monomer and dimer is consistent with the helical structures shown (Fig. 4C,D). In addition, single-stranded cleavage of predicted double-stranded regions can occur at the last 2 bp of a helix, as observed in McGraw et al. (2009), which can account for patterns seen near G10, G25, and C26. Of the 24 strong hits observed, 19 are consistent with the proposed secondary structure, while the other five are in regions that may be due to breathing, allowing access to single-strand nucleases and stacking allowing access to RNase V1, which is known to cleave such regions (Lowman and Draper 1986). The potential for an ensemble of dimer species thus exists, but the data suggest that they would be closely related (see Conclusions).

Structure mapping of $1 / 99 \Delta 3$ bp monomer and dimer was also performed, and monomer and dimer mapping was identical to 1/99 WT monomer and dimer, with extensive protection of L4 in the dimer, supporting generalization of the effects to this strong activator (Supplemental Fig. S3A-D). Lastly, we note that the extended dimer structures in WT RNA are $28 \mathrm{bp}$ in length, which is below the minimal activating length of 33 bp (Manche et al. 1992; Zheng and Bevilacqua 2004), and which implicates helical contributions from the two adjacent 14-bp stem-loops. These three helical segments together would make a 56-bp dsRNA, which would be a strong PKR activator, as observed herein. The ability of multiple shorter helical fragments to promote activation has been noted previously in aptamers, pseudoknots, TAR, and the HCV IRES (Bevilacqua et al. 1998; Cohen-Chalamish et al. 2009; Shimoike et al. 2009; Heinicke 2010; Toroney et al. 2010). We note that similar activation of PKR by dimers of $1 / 99 \Delta 3 \mathrm{bp}$, WT, and $+3 \mathrm{bp}$ constructs at $0.1 \mu \mathrm{M}$ RNA dimer (Supplemental Fig. S2B), supports the importance of regions outside of the 28-bp P4 dimerizing region, or else WT and especially +3 bp should activate more potently, given the above minimal activating length of $33 \mathrm{bp}$.

Lastly, we examined possible dimer folds using three secondary structure prediction programs: mfold $\mathrm{v} 3.5$, RNAstructure, and pknotsRG (Zuker 2003; Reeder et al.
2007; Reuter and Mathews 2010). The bimolecular fold option was used for RNAstructure, while two copies of HDV with an $A_{6}$ linker were used for mfold and pknotsRG. Without constraints, all three programs predict the extended kissing loop shown in Figure 4D as the lowest free energy structure, and are consistent with our dimer model. Our modeled stem-loop structures located on the $5^{\prime}-$ and $3^{\prime}$-ends of this kissing region were present in most optimal and suboptimal structures.

\section{CONCLUSIONS}

In this study we examined the ability of the semiglobular $\mathrm{HDV}$ ribozyme to activate PKR. The ribozyme is mostly globular, but has a protruding 13-bp P4 pairing region. This region seemed the most likely one to promote activation of PKR, given that PKR is known to bind and be activated by long dsRNA. We thus examined PKR activation as a function of the length of $\mathrm{P} 4$ by preparing shortened and lengthened P4 variants. Surprisingly, 1/99 $\Delta 3$ bp was the most potent PKR activator, despite having fewer base pairs in the dimerized $\mathrm{P} 4$ region. It thus appears that the two adjacent 14-bp stem-loops contribute to activation, which was as high in magnitude as that of 79-bp dsRNA.

Correlation between extent of dimer formation, as determined by native PAGE, and activation of PKR was observed. Dimer formation was observed to be facilitated in the $1 / 99 \Delta 3$-bp variant, which was likely due to destabilization of P4 upon removal of base pairs. To test whether dimer was the activating species, 1/99 WT and 1/99 $\Delta 3 \mathrm{bp}$ HDV monomer and dimer species were gently isolated from a native gel, confirmed to retain their original oligomeric states, and tested for activation of PKR. Monomers failed to activate PKR, while dimers were potent activators, activating PKR with affinity similar to 79-bp dsRNA. Structure mapping of 1/99 WT HDV monomer and dimers revealed that monomer folds as a native secondary structure of the ribozyme, but that the dimer species rearranges into an extended species consistent with the model in Figure 4D. Given the broad nature of the band on the native gels (e.g., Fig. 3A), it remains possible that there is an ensemble of related conformations in the dimer population.

The RNA dimer of the HDV ribozyme essentially doubles the number of contiguous base pairs, approaching the activating length, which is then likely exceeded by interaction with peripheral RNA regions. We observed a similar phenomenon in HIV TAR, where RNA dimerization drives PKR dimerization and activation (Heinicke et al. 2009). Indeed, most stem-loops dimerize at high concentration, owing to their self- 
complementary nature. Moreover, stem-loops can even polymerize, forming aggregates at high concentrations or with special sequences, which can activate PKR (Venkataraman et al. 2010). From the present study, it is clear that a semiglobular RNA can misfold into a dimer and activate the innate immune response protein, PKR. This contributes to the growing list of RNAs capable of activating PKR (Nallagatla et al. 2011) and provides a potential link between RNA misfolding and disease via innate immunity.

\section{MATERIALS AND METHODS}

\section{Protein expression and purification}

Full-length PKR containing an N-terminal (His) ${ }_{6}$ tag was cloned into pET-28a (Novagen, Inc.) and transformed into E. coli BL21(DE3) Rosetta cells (Novagen, Inc.) as previously described (Bevilacqua and Cech 1996; Zheng and Bevilacqua 2004; Nallagatla et al. 2007). Briefly, cells were sonicated and protein was purified by a $\mathrm{Ni}^{2+}$-agarose column (Qiagen, Inc.). A glutathione S-transferase (GST) $-\lambda$-Protein Phosphatase (PPase) fusion protein was cloned, expressed, and purified to treat partially phosphorylated PKR before PKR activation assays. $\lambda$-PPase was subcloned from pET21a containing $\lambda$-PPase and GST-PKR into pET-42a and transformed into E. coli BL21(DE3)pLysS cells. Protein was purified by sonication and filtration through a 0.45 -micron filter, followed by GST column purification (Novagen). GST- $\lambda$-PPase was dialyzed into storage buffer: $50 \mathrm{mM}$ HEPES ( $\mathrm{pH} 7.5$ ), $100 \mathrm{mM} \mathrm{NaCl}, 0.1$ $\mathrm{mM} \mathrm{MnCl} 2,0.1 \mathrm{mM}$ EGTA, $2 \mathrm{mM}$ DTT, $0.01 \%$ Brij 35, and $50 \%$ glycerol (New England Biolabs, NEB).

Dephosphorylated PKR was prepared by treatment with GST$\lambda$-PPase using a standard NEB dephosphorylation protocol (Cohen and Cohen 1989). During dephosphorylation, GST$\lambda$-PPase was present at $1 / 4$ the concentration of PKR. An additional glutathione column was used to separate PKR from GST- $\lambda$-PPase, and then PKR was dialyzed into a storage buffer of $10 \mathrm{mM}$ Tris $(\mathrm{pH}$ 7.6), $50 \mathrm{mM} \mathrm{KCl}, 2 \mathrm{mM} \mathrm{MgOAc}, 10 \%$ glycerol, and $7 \mathrm{mM}$ $\beta$-mercaptoethanol.

\section{Plasmid and RNA preparation}

HDV variants $1 / 99 \Delta 3$ bp and $1 / 99+3$ bp were prepared using QuikChange site-directed mutagenesis (Stratagene) to remove or introduce nucleotides in pUC19 plasmid containing -54/271 HDV sequence (accession number M28267, GenBank) (Makino et al. 1987; Diegelman-Parente and Bevilacqua 2002). Plasmids were linearized with BfaI for run-off T7 transcription (Ambion) (Chadalavada et al. 2000). Self-cleaved HDV RNAs were excised and soaked overnight at $4^{\circ} \mathrm{C}$ in $\mathrm{TEN}_{250}(10 \mathrm{mM}$ Tris at $\mathrm{pH} 7.5,1 \mathrm{mM}$ EDTA, and $250 \mathrm{mM} \mathrm{NaCl}$ ). Subsequently, RNAs were ethanol precipitated and resuspended in TE $(10 \mathrm{mM}$ Tris at $\mathrm{pH} 7.5$ and $1 \mathrm{mM}$ EDTA). Concentrations were determined spectrophotometrically. $5^{\prime}$-end-labeled RNAs were prepared by polynucleotide kinase treatment in the presence of $\left[\gamma^{-32} \mathrm{P}\right] \mathrm{ATP}$.

\section{Native gel analysis of HDV dimerization}

Analytical native gel electrophoresis of RNA was performed for two reasons. The first was to analyze the monomeric and dimeric content of HDV ribozyme preparations (shown in Fig. 2A), and the other was to assess the retention of monomer and dimer formation after isolation of these species from preparative native gels (shown in Figs. 3A, 4B); see below for further details. Native gels contained $10 \%$ of $29: 1$ cross-linking polyacrylamide. The buffer both in the gel and for electrophoresis was $0.5 \times \mathrm{TBE}(50$ $\mathrm{mM}$ Tris base, $40 \mathrm{mM}$ boric acid, and $0.5 \mathrm{mM}$ EDTA) or $\mathrm{THEM}_{4}$ (34 mM Tris base, $66 \mathrm{mM}$ HEPES, $0.1 \mathrm{mM}$ EDTA, and $4 \mathrm{mM}$ $\mathrm{MgCl}_{2}$ ). The buffer $0.5 \times$ TBE was used in most cases, as $\mathrm{THEM}_{4}$ and $0.5 \times \mathrm{TBE}$ were found to have similar effects on the ratio of monomer to dimer. Native gels were run at $300 \mathrm{~V}$ and $16^{\circ} \mathrm{C}$ for 45 min prior to loading samples. In general, samples were fractionated for $\sim 2 \mathrm{~h}$.

For the gel in which dimer and monomer content of non-native gel-purified RNAs were analyzed (Fig. $2 \mathrm{~A})$, trace amounts $(\sim 1 \mathrm{nM})$ of $5^{\prime}$-end-labeled RNA was added to various concentrations of unlabeled RNA and renatured in TE by incubating at $90^{\circ} \mathrm{C}$ for $1 \mathrm{~min}$, followed by incubating at $55^{\circ} \mathrm{C}$ for $10 \mathrm{~min}$. In this experiment, samples in TE were then treated in one of three ways, by adding an equal volume to the following: (1) TE, (2) $\mathrm{TEK}_{400} \mathrm{M}_{20}(10 \mathrm{mM}$ Tris at $\mathrm{pH} 7.5,1 \mathrm{mM}$ EDTA, $400 \mathrm{mM} \mathrm{KCl}$, and $20 \mathrm{mM} \mathrm{MgCl}_{2}$ ), or (3) $\mathrm{TEN}_{400} \mathrm{M}_{20}(10 \mathrm{mM}$ Tris at $\mathrm{pH} 7.5,1 \mathrm{mM}$ EDTA, $400 \mathrm{mM}$ $\mathrm{NaCl}$, and $20 \mathrm{mM} \mathrm{MgCl}_{2}$ ), followed by another incubation at room temperature for $10 \mathrm{~min}$. Final concentrations in (2) and (3) were $200 \mathrm{mM} \mathrm{KCl}$ (or $\mathrm{NaCl}$ ) and $10 \mathrm{mM} \mathrm{MgCl}_{2}$. In some cases, the final concentration of monovalent salt was decreased from 200 to $100 \mathrm{mM}$, as indicated in the main text. Prior to native gel analysis, $5 \%$ glycerol was added to the samples.

Confirmation of the upper and lower bands as dimer and monomer was achieved by comparison to 78-nt transcripts of tRNA dimer and monomers (Fig. 2A), prepared as described elsewhere (Wittenhagen and Kelley 2002; Roy et al. 2005). The $1 / 99 \Delta 3$-bp WT, at $93 \mathrm{nt}$, is $15 \mathrm{nt}$ or $19 \%$ longer than tRNA. We found that the monomer and dimer migrated $\sim 22 \%$ and $25 \%$ slower for HDV RNA than tRNA, which is in line with the $19 \%$ greater length of HDV RNA, with the P4 extension leading to less compaction and slightly slower mobility in HDV RNA than expected based on tRNA. Moreover, the dimer band only formed at high HDV RNA concentrations (Fig. 2A, cf. lanes 3-5 and lanes 6$8)$, confirming that it is a multimer. That the spacing between the monomer and dimer of tRNA (which is a 78-nt transcript) is nearly the same as the spacing between the monomer and dimer of $1 / 99 \Delta 3$ bp (which is a 93-nt transcript) on the native gel (Fig. 2A) confirms that the upper band of HDV RNA is a dimer. A kissing loop complex with protection of L4 further confirms this assignment.

Native gels were also run to assess retention of the monomeric and dimeric states. Analytical gels are shown in Figures $3 \mathrm{~A}$ and $4 \mathrm{~B}$ and generally ${ }^{3}$ omitted the high-temperature renaturation in an effort to preserve any dimer, and were exposed to a storage screen for $16 \mathrm{~h}$ and analyzed on a PhosphorImager (Molecular Dynamics).

\section{Purification of RNA monomers and dimers from native gels}

Native gels were used to prepare monomer and dimer RNA. In most cases, 20 or $50 \mu \mathrm{M}$ RNA in TE was renatured in the presence

\footnotetext{
${ }^{3}$ The only exception was certain lanes desired to be monomer, such as Fig. $3 \mathrm{~A}$, lane 2 , in which a renaturation was conducted.
} 
of radiolabeled RNA by incubating at $90^{\circ} \mathrm{C}$ for $1 \mathrm{~min}$, followed by incubation at $55^{\circ} \mathrm{C}$ for $10 \mathrm{~min}$. In some cases, 1/99 WT and $1 / 99+$ 3-bp RNA dimers were prepared by incubating in $\mathrm{TEN}_{100}$ at $95^{\circ} \mathrm{C}$ for $4 \mathrm{~min}$, followed by slow cooling to $40^{\circ} \mathrm{C}$ over $1.5 \mathrm{~h}$ (Supplemental Fig. S2). Next, 5\% glycerol was added to the RNA, and it was fractionated on a $0.5 \times$ TBE native gel for $2 \mathrm{~h}$. Monomer and dimer RNA bands were visualized by UV shadowing and excised. RNAs were crushed and soaked overnight in $\mathrm{TEN}_{250}$ at $4^{\circ} \mathrm{C}$, ethanol precipitated the next day, resuspended in $\mathrm{TE}$, and stored at $-20^{\circ} \mathrm{C}$. All radiolabeled samples were refractionated on an analytical native gel, as described above, to assess retention of monomer and dimer state.

\section{PKR activation assays}

RNAs were tested for their ability to activate PKR, as shown in Figures $2 \mathrm{~B}$ and $3 \mathrm{~B}$. GST- $\lambda$-PPase-treated PKR $(0.6 \mu \mathrm{M})$ was incubated with various concentrations of RNA, in a final concentration of $20 \mathrm{mM}$ HEPES ( $\mathrm{pH} 7.5$ ), $5 \mathrm{mM} \mathrm{MgCl}$, 50 or $100 \mathrm{mM}$ $\mathrm{NaCl}, 1.5 \mathrm{mM}$ DTT, $100 \mu \mathrm{M}$ ATP (Ambion), and $15 \mu \mathrm{Ci}$ $\left[\gamma^{-32} \mathrm{P}\right]$ ATP. Heterogeneous RNA species, which are a mixture of monomer and dimer species, were prepared by incubating $4 \mathrm{x}$ concentration RNA at $90^{\circ} \mathrm{C}$ for $1 \mathrm{~min}$, followed by $55^{\circ} \mathrm{C}$ for 10 min (e.g., Fig. 2B). RNAs that were isolated from a native gel as monomer or dimer (as described in the previous subsection) were subjected to this $90^{\circ} \mathrm{C}$ step (e.g., Figs. 3A, 4B) only for monomer preparations. For certain RNAs, an equal volume of $\mathrm{TEN}_{400} \mathrm{M}_{20}$ or $\mathrm{TEN}_{200} \mathrm{M}_{20}$ was added, followed by incubation at room temperature for $10 \mathrm{~min}$ to give $2 \times$ stocks that were then added to an appropriate $\mathrm{PKR}$ reaction mixture.

Prior to activation assays, RNA isolated as monomers was renatured briefly at $90^{\circ} \mathrm{C}$ to help remove any dimer and retain pure monomeric identity as previously described (Heinicke et al. 2009), and the final concentrations of RNA did not exceed $0.6 \mu \mathrm{M}$ to avoid the increased the likelihood of introducing small amounts of dimer into renatured monomer samples; RNAs isolated at dimers were not heated at this step. PKR activation reaction mixtures were incubated at $30^{\circ} \mathrm{C}$ for $10 \mathrm{~min}$, quenched with SDS loading buffer, and loaded on 10\% SDS-PAGE (Pierce). Gels were exposed to a storage PhosphorImager screen, and intensities of the PKR bands were quantified using a PhosphorImager (Molecular Dynamics). In activation assay gels, a no-RNA lane is provided, and phosphorylation activities are normalized to $0.01 \mu \mathrm{M}$ 79-bp RNA. Fold-effects are reported for relative activation after the no-RNA background was subtracted.

\section{Enzymatic structure mapping of RNA}

RNA monomers were renatured at $3 \mu \mathrm{M}$ in water by incubating at $90^{\circ} \mathrm{C}$ for $3 \mathrm{~min}$ to remove any dimer, while dimer samples were not renatured (Heinicke et al. 2009). Final concentrations of monomer and dimer RNAs for both native and denaturing structure mapping reactions were 1 and $0.5 \mu \mathrm{M}$, respectively, to give the same total concentration of nucleotides, which allowed the same amount of ribonuclease to be used for mapping monomeric and dimeric RNAs. Ribonuclease concentrations were $4 \mathrm{ng} / \mathrm{mL}$ RNase A, $0.001 \mathrm{U} / \mu \mathrm{L}$ RNase T1, $5 \times 10^{-4} \mathrm{U} / \mu \mathrm{L}$ RNase T2, and $0.002 \mathrm{U} / \mu \mathrm{L}$ RNase V1. Higher concentrations of ribonucleases were tested, but resulted in nonspecific cleavage. Ribonucleases were diluted into $10 \mathrm{mM}$ Tris ( $\mathrm{pH} 8.0), 10 \%$ glycerol, and
$1 \mathrm{mM}$ DTT as needed. Native RNA cleavage reactions were performed in $20 \mathrm{mM}$ MES ( $\mathrm{pH} 6.0$ ), $50 \mathrm{mM} \mathrm{NaCl}$, and $10 \mathrm{mM}$ $\mathrm{MgCl}_{2}$ at $37^{\circ} \mathrm{C}$ for $15-60 \mathrm{~min}$. Denaturing RNA cleavage reactions, used as sequencing lanes, were $0.1 \mathrm{U} / \mu \mathrm{L} \mathrm{T} 1,4.7 \mathrm{M}$ urea, $14 \mathrm{mM}$ sodium citrate ( $\mathrm{pH} 3.5$ ), and $0.7 \mathrm{mM} \mathrm{EDTA}$ at $50^{\circ} \mathrm{C}$ for $15 \mathrm{~min}$, and hydrolysis reactions were $50 \mathrm{mM} \mathrm{Na} 2 \mathrm{CO}_{3} / \mathrm{NaHCO}_{3}$ (pH 9.0) and $1 \mathrm{mM}$ EDTA at $90^{\circ} \mathrm{C}$ for $4 \mathrm{~min}$. Fractionated samples were loaded onto 12\% PAGE/TBE/8.3 M urea denaturing gel.

\section{SUPPLEMENTAL MATERIAL}

Supplemental material is available for this article.

\section{ACKNOWLEDGMENTS}

Special thanks to Durga Chadalavada for assistance with HDV preparation. We also thank Durga Chadalavada and Chelsea Hull for helpful comments on the manuscript. This work was supported by National Institutes of Health grant GM-58709 (P.C.B.).

Received June 5, 2012; accepted September 20, 2012.

\section{REFERENCES}

Been MD, Wickham GS. 1997. Self-cleaving ribozymes of hepatitis delta virus RNA. Eur J Biochem 247: 741-753.

Ben-Asouli Y, Banai Y, Pel-Or Y, Shir A, Kaempfer R. 2002. Human interferon- $\gamma$ mRNA autoregulates its translation through a pseudoknot that activates the interferon-inducible protein kinase PKR. Cell 108: 221-232.

Bevilacqua PC, Cech TR. 1996. Minor-groove recognition of doublestranded RNA by the double-stranded RNA-binding domain from the RNA-activated protein kinase PKR. Biochemistry 35: 9983-9994.

Bevilacqua PC, George CX, Samuel CE, Cech TR. 1998. Binding of the protein kinase PKR to RNAs with secondary structure defects: Role of the tandem A-G mismatch and noncontiguous helixes. Biochemistry 37: 6303-6316.

Branch AD, Robertson HD. 1991. Efficient trans cleavage and a common structural motif for the ribozymes of the human hepatitis $\delta$ agent. Proc Natl Acad Sci 88: 10163-10167.

Brown TS, Bevilacqua PC. 2005. Method for assigning doublestranded RNA structures. Biotechniques 38: 368-372.

Brown TS, Chadalavada DM, Bevilacqua PC. 2004. Design of a highly reactive HDV ribozyme sequence uncovers facilitation of RNA folding by alternative pairings and physiological ionic strength. J Mol Biol 341: 695-712.

Chadalavada DM, Knudsen SM, Nakano S, Bevilacqua PC. 2000. A role for upstream RNA structure in facilitating the catalytic fold of the genomic hepatitis delta virus ribozyme. J Mol Biol 301: 349-367.

Circle DA, Neel OD, Robertson HD, Clarke PA, Mathews MB. 1997. Surprising specificity of PKR binding to delta agent genomic RNA. RNA 3: 438-448.

Cohen PT, Cohen P. 1989. Discovery of a protein phosphatase activity encoded in the genome of bacteriophage $\lambda$. Probable identity with open reading frame 221. Biochem J 260: 931-934.

Cohen-Chalamish S, Hasson A, Weinberg D, Namer LS, Banai Y, Osman F, Kaempfer R. 2009. Dynamic refolding of IFN- $\gamma$ mRNA enables it to function as PKR activator and translation template. Nat Chem Biol 5: 896-903.

Diegelman-Parente A, Bevilacqua PC. 2002. A mechanistic framework for co-transcriptional folding of the HDV genomic ribozyme in the presence of downstream sequence. J Mol Biol 324: 1-16.

Ferre-D'Amare AR, Zhou K, Doudna JA. 1998. Crystal structure of a hepatitis delta virus ribozyme. Nature 395: 567-574. 
Heinicke LA. 2010. Regulation of protein kinase PKR by higher-order RNA secondary and tertiary structures. The Pennsylvania State University, Department of Chemistry, p. 184. University Park, PA.

Heinicke LA, Wong CJ, Lary J, Nallagatla SR, Diegelman-Parente A, Zheng X, Cole JL, Bevilacqua PC. 2009. RNA dimerization promotes PKR dimerization and activation. J Mol Biol 390: 319-338.

Heinicke LA, Nallagatla SR, Hull CM, Bevilacqua PC. 2011. RNA helical imperfections regulate activation of the protein kinase PKR: Effects of bulge position, size, and geometry. RNA 17: 957-966.

Karayiannis P. 1998. Hepatitis D virus. Rev Med Virol 8: 13-24.

Lai MM. 1995. The molecular biology of hepatitis delta virus. Annu Rev Biochem 64: 259-286.

Lazinski DW, Taylor JM. 1993. Relating structure to function in the hepatitis delta virus antigen. J Virol 67: 2672-2680.

Lazinski DW, Taylor JM. 1995. Intracellular cleavage and ligation of hepatitis delta virus genomic RNA: Regulation of ribozyme activity by cis-acting sequences and host factors. J Virol 69: 1190-1200.

Lemaire PA, Anderson E, Lary J, Cole JL. 2008. Mechanism of PKR activation by dsRNA. J Mol Biol 381: 351-360.

Lowman HB, Draper DE. 1986. On the recognition of helical RNA by cobra venom V1 nuclease. J Biol Chem 261: 5396-5403.

Makino S, Chang MF, Shieh CK, Kamahora T, Vannier DM, Govindarajan S, Lai MM. 1987. Molecular cloning and sequencing of a human hepatitis delta ( $\delta$ ) virus RNA. Nature 329: 343-346.

Manche L, Green SR, Schmedt C, Mathews MB. 1992. Interactions between double-stranded RNA regulators and the protein kinase DAI. Mol Cell Biol 12: 5238-5248.

McGraw AP, Mokdad A, Major F, Bevilacqua PC, Babitzke P. 2009. Molecular basis of TRAP-5'SL RNA interaction in the Bacillus subtilis trp operon transcription attenuation mechanism. RNA 15: $55-66$.

Nallagatla SR, Hwang J, Toroney R, Zheng X, Cameron CE, Bevilacqua PC. 2007. 5'-triphosphate-dependent activation of PKR by RNAs with short stem-loops. Science 318: 1455-1458.
Nallagatla SR, Toroney R, Bevilacqua PC. 2011. Regulation of innate immunity through RNA structure and the protein kinase PKR. Curr Opin Struct Biol 21: 119-127.

Reeder J, Steffen P, Giegerich R. 2007. pknotsRG: RNA pseudoknot folding including near-optimal structures and sliding windows. Nucleic Acids Res 35: W320-W324.

Reuter JS, Mathews DH. 2010. RNAstructure: Software for RNA secondary structure prediction and analysis. BMC Bioinformatics 11: 129. doi: 10.1186/1471-2105-11-129.

Robertson HD, Manche L, Mathews MB. 1996. Paradoxical interactions between human delta hepatitis agent RNA and the cellular protein kinase PKR. J Virol 70: 5611-5617.

Roy MD, Wittenhagen LM, Kelley SO. 2005. Structural probing of a pathogenic tRNA dimer. RNA 11: 254-260.

Shimoike T, McKenna SA, Lindhout DA, Puglisi JD. 2009. Translational insensitivity to potent activation of PKR by HCV IRES RNA. Antiviral Res 83: 228-237.

Toroney R, Nallagatla SR, Boyer JA, Cameron CE, Bevilacqua PC. 2010. Regulation of PKR by HCV IRES RNA: Importance of domain II and NS5A. J Mol Biol 400: 393-412.

Venkataraman S, Dirks RM, Ueda CT, Pierce NA. 2010. Selective cell death mediated by small conditional RNAs. Proc Natl Acad Sci 107: 16777-16782.

Wang KS, Choo QL, Weiner AJ, Ou JH, Najarian RC, Thayer RM, Mullenbach GT, Denniston KJ, Gerin JL, Houghton M. 1986. Structure, sequence and expression of the hepatitis delta $(\delta)$ viral genome. Nature 323: 508-514.

Wittenhagen LM, Kelley SO. 2002. Dimerization of a pathogenic human mitochondrial tRNA. Nat Struct Biol 9: 586-590.

Zheng X, Bevilacqua PC. 2004. Activation of the protein kinase PKR by short double-stranded RNAs with single-stranded tails. RNA 10: 1934-1945.

Zuker M. 2003. Mfold web server for nucleic acid folding and hybridization prediction. Nucleic Acids Res 31: 3406-3415. 

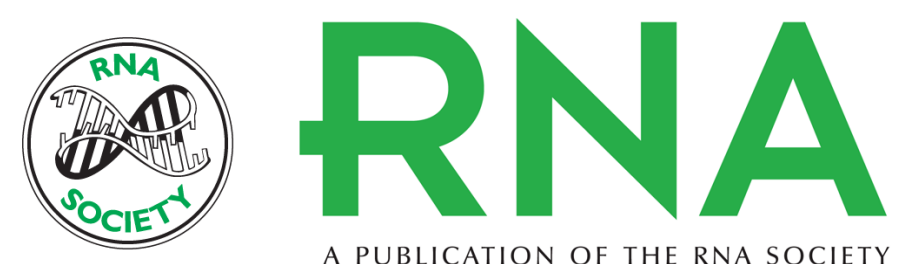

A PUBLICATION OF THE RNA SOCIETY

\title{
Activation of PKR by RNA misfolding: HDV ribozyme dimers activate PKR
}

\author{
Laurie A. Heinicke and Philip C. Bevilacqua
}

RNA 2012 18: $2157-2165$ originally published online October 25,2012

Access the most recent version at doi:10.1261/rna.034744.112

\section{Supplemental http://rnajournal.cshlp.org/content/suppl/2012/10/11/rna.034744.112.DC1 \\ Material}

References This article cites 37 articles, 14 of which can be accessed free at: http://rnajournal.cshlp.org/content/18/12/2157.full.html\#ref-list-1

\section{License}

Email Alerting Receive free email alerts when new articles cite this article - sign up in the box at the Service top right corner of the article or click here. 